\title{
Special issue: 'Lie Computations'
}

\author{
Guest Editors: Gérard Jacob and Pierre-Vincent Koseleff
}

This special issue is an outgrowth of the MEDICIS thematic workshop on Lie Computations that was held at the Centre International de Rencontres Mathématiques in Marseilles in November 1994. It was jointly sponsored by the Groupe de Recherche MEDICIS, the CIRM (Société Mathématique de France), and the European project INTAS 93-30

The conference brought together mathematicians, computer scientists, physicists and automaticians interested in the subject of Lie Computations. 'Lie Computations' are involved in many research fields, and especially in fundamental physics, statistical physics and theory of control. The field concerns Lie techniques - Lie groups, Lie algebras, Lie series, symplectic integrators, Poisson algebras - and the use of computer algebra. Recent techniques and results have been obtained concerning structural analysis as well as the improvement of precision in numerical integration, by the use of combinatorial or algebraic identities.

Computational aspects in free Lie algebras are presented in the paper by ANDARY. They are also discussed in the case of finite-dimensional Lie algebras in the article by COHEN, DE GRAAF and RÓNYAI, and in the paper by GERDT and KORNYAK. Noncommutative algebras defined by generators and relations are considered in the paper by COJOCARU and UFNAROVSKI.

The paper by DuCHAMP, KLYACHKO, KROB and THIBON deals with noncommutative symmetric functions, and highlights connections with formulae in theoretical physics. Lie formalism in physics is presented in the paper by DRAGT (Hamiltonian and Lagrangian Optics), and also that by CAPRASSE (Gauge theory). Finally, aspects of theory of control are discussed in the paper by SACHKOV, and applications to differential algebras or algebras of differential operators are examined in the paper by GINOCCHIO.

Of course, there are many other strong links between all the collected papers in the special issue. In keeping with the general spirit of the thematic workshop, the papers are also of interest to non-specialists.

The Editors would like to thank the authors for their patience, the Editor-in-Chief, Daniel Krob, for having accepted this publication, and the Publishing Editor, Bryony Watson, for having managed it so well. 